\title{
Host Defense Molecule Polymorphisms Influence the Risk for Immune-Mediated Complications in Chronic Granulomatous Disease
}

\author{
Charles B. Foster, ${ }^{\star}$ Thomas Lehrnbecher, ${ }^{\star}$ Femke Mol, ${ }^{\star}$ Seth M. Steinberg, ${ }^{\ddagger}$ David J. Venzon, ${ }^{\ddagger}$ Thomas J. Walsh, ${ }^{\star}$ \\ Deborah Noack, $\$$ Julie Rae, Jerry A. Winkelstein, ${ }^{\uparrow}$ John T. Curnutte, ${ }^{\| \star *}$ and Stephen J. Chanock ${ }^{\star}$ \\ *Immunocompromised Host Section, Pediatric Oncology Branch; ${ }^{\ddagger}$ Biostatistics and Data Management Section, National Cancer Institute, \\ National Institutes of Health, Bethesda, Maryland 20892; ${ }^{\S}$ Department of Molecular and Experimental Medicine, The Scripps Research \\ Institute, La Jolla, California 92037; "Department of Immunology, Genentech, Inc., South San Francisco, California 94080; ${ }^{\text {II Department }}$ \\ of Pediatrics, The Johns Hopkins University School of Medicine, Baltimore, Maryland 21218; and **Department of Pediatrics, Stanford \\ University School of Medicine, Stanford, California 94305
}

\begin{abstract}
Chronic granulomatous disease (CGD) is an inherited disorder of phagocyte function in which defective superoxide production results in deficient microbicidal activity. CGD patients suffer from recurrent, life-threatening infections, and nearly half develop chronic gastrointestinal (GI) complications (colitis, gastric outlet obstruction, or perirectal abscess) and/or autoimmune/rheumatologic disorders (AIDs). To identify genetic modifiers of disease severity, we studied a cohort of 129 CGD patients, in whom seven candidate genes (myeloperoxidase [MPO], mannose binding lectin [MBL], Fc $\gamma$ receptors IIa, IIIa, IIIb, TNF- $\alpha$, and IL-1 receptor antagonist), each containing a physiologically relevant polymorphism predicted to influence the host inflammatory response, were selected for analysis. Genotypes of MPO $(P=0.003)$ and Fc $\gamma$ RIIIb $(P=0.007)$ were strongly associated with an increased risk for GI complications, while an Fc $\gamma$ RIIa $(P=0.05)$ genotype was suggestive for an association. Patients with all three associated genotypes had the highest risk for GI complications $(P<0.0001)$. The risk of AIDs was strongly associated with variant alleles of MBL $(P=0.01)$ and weakly associated with an Fc $\gamma$ RIIa genotype $(P=0.04)$. Patients with variant forms of both MBL and Fc $\gamma$ RIIa had the highest risk of developing an AID $(P=$ 0.003). (J. Clin. Invest. 1998. 102:2146-2155.) Key words: myeloperoxidase $\cdot \mathrm{Fc}$ receptor $\cdot$ mannose binding lectin $•$ gastric outlet obstruction $\bullet$ rheumatological disorders
\end{abstract}

\section{Introduction}

Chronic granulomatous disease (CGD) $)^{1}$ is an inherited disorder of phagocyte function in which defective or absent superoxide production results in deficient microbicidal activity (14). Patients with CGD suffer from frequent, life-threatening

Address correspondence to Stephen J. Chanock, Immunocompromised Host Section, Pediatric Oncology Branch, National Cancer Institute, National Institutes of Health, Building 10, Room 13N240, 9000 Rockville Pike, Bethesda, MD 20892. Phone: 301-402-1444; FAX: 301-402-0575; E-mail: SC83a@nih.gov

Received for publication 31 August 1998 and accepted in revised form 27 October 1998.

J. Clin. Invest.

(C) The American Society for Clinical Investigation, Inc. 0021-9738/98/12/2146/10 \$2.00

Volume 102, Number 12, December 1998, 2146-2155

http://www.jci.org infections with bacterial and fungal pathogens (5). Nearly half of all CGD patients also develop significant chronic complications. These include gastric or urinary tract obstruction secondary to granuloma formation, granulomatous ileocolitis, perirectal abscesses, and rheumatologic disorders (6-17). The pathophysiologic processes contributing to these complications of CGD are poorly understood, but most certainly are mediated by NADPH oxidase-independent inflammatory pathways. Since the frequency and severity of both infectious and immunologically mediated complications of CGD vary among affected individuals, suggesting that aberrant immunologic responses may mediate chronic complications in some individuals, we hypothesized that alterations in pathways other than the NADPH oxidase might influence these complications $(18,19)$.

The molecular basis of CGD is a mutation in one of four genes of the NADPH oxidase $(1,20)$. In X-linked recessive (XLR) CGD, the most common form of the disease, molecular analysis of several hundred patients has revealed a diverse spectrum of mutations $(21,22)$, making it difficult to associate specific mutations with disease phenotype, as has been suggested for cystic fibrosis and classical hemophilia (factor VIII deficiency) (23-25). However, among CGD subtypes, it has been proposed that the autosomal recessive (AR) forms may be associated with milder disease (26). The extent to which environmental and secondary genetic factors influence phenotypic expression of disease is unknown.

To study potential genetic modifiers of disease severity in 129 patients with CGD, seven candidate genes were selected for genetic subtyping of well-defined variant alleles. These polymorphic genes included TNF- $\alpha$ (27), IL-1 receptor antagonist (IL1RN) (28), mannose binding lectin (MBL) (29-31), Fc- $\gamma$ receptor IIa (Fc $\gamma$ RIIa) $(32,33)$, Fc $\gamma$ RIIIa $(34,35)$, Fc $\gamma-$ RIIIb (36), and myeloperoxidase (MPO) (37, 38). Candidate genes were chosen because of their central role in innate immunity or phagocyte biology, high frequency (5-40\%) of variant alleles in the general population, and the presence of biological and/or clinical correlates, strongly suggesting a difference in activity that may modify host immune response (38-51). It is possible that subtle changes (polymorphisms) in genes of immune function, which may have little or no effect in the general population, could assume greater significance in individuals with defects in host defense systems, such as CGD. In this setting, one would predict that the coinheritance of sus-

1. Abbreviations used in this paper: AID, autoimmune/rheumatologic disorder; AR, autosomal recessive; CGD, chronic granulomatous disease; DLE, discoid lupus erythematosus; Fc $\gamma$ RIIa, Fc- $\gamma$ receptor IIa; GI, gastrointestinal; GU, gastrourinary; IL1RN, interleukin-1 receptor antagonist; MBL, mannose binding lectin; MPO, myeloperoxidase; XLR, X-linked recessive. 
ceptibility genes may influence the frequency and severity of infectious and inflammatory complications.

\section{Methods}

Database analysis. This study retrospectively investigated the natural history of CGD in 129 patients followed by Dr. John Curnutte at a national referral center. A confirmed diagnosis of CGD, adequate clinical history, and banked genomic DNA were required for inclusion in the study. The diagnosis of CGD was confirmed by absent or defective production of superoxide, Western blot analysis, and molecular characterization of a defect in one of four genes, gp91 ${ }^{\text {phox }}$, p67 $67^{\text {hox }}, \mathrm{p} 47^{\text {phox }}$, or $\mathrm{p} 22^{\text {phox }}$. We obtained DNA from 104 patients with XLR (gp91 phox $)$ CGD and 25 patients with AR CGD, including 16 deficient in $\mathrm{p} 47^{\text {phox }}, 6$ in $\mathrm{p} 67^{\text {phox }}$, and 3 in $\mathrm{p} 22^{\text {phox }}$. The study population consisted of both living and deceased pediatric and adult patients. The population included 105 Caucasian Americans, 8 Asian/Polynesian Americans, 7 African Americans, 2 Native Americans, 1 patient of Indian ancestry, and 6 of unspecified background. 116 patients were male and 13 were female.

All clinical information was extracted and organized into a database prior to genotypic analysis of genomic DNA and was delinked from unique patient identifiers, such as date of birth or date of death. Clinical data from patient records were cross-referenced with reports submitted to the National Institutes of Health's Chronic Granulomatous Disease Registry of the Immune Deficiency Foundation (Towson, MD). The data gathered included demographic information (gender, race, and subtype of CGD), age range of death or last contact, documentation of autoimmune/rheumatologic disorder (AID), fungal infections, nonpulmonary abscess (e.g., hepatic, chest wall, brain, or intra-abdominal), perirectal abscess (or fistulae), colitis, and granulomatous (including gastric, urinary, and esophageal outlet obstructions and testicular granulomas) complications.

Tubes of genomic DNA were linked directly to the completed clinical database with a unique identifier. The protocol for anonymous analysis of genetic information from banked genomic DNA samples was approved by the Institutional Review Board of the National Cancer Institute.

Polymorphism analysis from genomic DNA. Genomic DNA (50 $\mathrm{ng} / \mu \mathrm{l}$ ) was initially isolated from peripheral blood samples by conventional methods for the purpose of molecular analysis of CGD subtypes $(1,21,52-54)$. Polymorphism analysis for each of the seven genes, MPO (38), FcyRIIa (32, 33), FcyRIIIb (36), MBL (29-31), IL1RN (28), TNF- $\alpha$ (27), and Fc $\gamma$ RIIIa $(34,35)$ was performed in duplicate according to modifications of protocols based upon previously reported assays. Primer pairs (including sequence primers when indicated), annealing temperatures, and detection methods used in PCRbased assays are as follows: MPO (F cgg tat agg cac aca atg gtg ag, R gca atg gtt caa gcg att ctt c, $58^{\circ} \mathrm{C}$, AciI digest), Fc $\gamma \mathrm{RIIa}$ (F gga aaa tcc cag aaa ttc tcg c, R caa cag cct gac tac cta tta cgc ggg, $55^{\circ} \mathrm{C}$, BstUI digest), Fc $\gamma$ RIIIb (NA1F ctc aat ggt aca ggg tgc tc, NA1R ggc ctg gct tga gat gag gt, $67^{\circ} \mathrm{C} ; \mathrm{NA} 2 \mathrm{~F}$ ctc att ggt aca gcg tgc tt, NA2R cac ctg tac tct cca ctg tcg tt, $67^{\circ} \mathrm{C}$, Control-MycF acg atg ccc ctc aac gtt agc tt and Control-MycR cgc aga tga aac tct ggt tca cca t, allele-specific PCR with Myc primers as positive control), MBL (F gga att cct gcc aga aag gta gag, R cag gca ggt tcc tct gga agg, $58^{\circ} \mathrm{C}$, Thermo Sequenase radiolabeled terminator cycle sequencing; Amersham Life Sciences, Inc., Cleveland, $\mathrm{OH}$ ), sequencing primer (act gtg acc tgt gag gat gcc caa aag), IL1RN (F ctc agc aac act cct at, R tcc tgg tct gca ggt aa, size fractionation of variable number tandem repeat polymorphism), and TNF- $\alpha$ (F caa aag aaa tgg agg caa tag gtt ttg agg gcc at, R agg gcg ggg aaa gaa tca ttc aac cag cgg aaa ac, $63^{\circ} \mathrm{C}$, NcoI digest). For Fc $\gamma$ RIIIa, a nested PCR was performed with the following sets of primers: ExternalF ata ttt aca gaa tgg cac agg, ExternalR gac ttg gta ccc agg ttg aa, $56^{\circ} \mathrm{C}$, and Internal $\mathrm{F}$ tca tca taa ttc tga ctt ct, Internal R ctt gag tga tgg tga tgt tc, $62^{\circ} \mathrm{C}$. The product of the internal (nested) PCR reaction was blotted onto a Hybond+ membrane and hybridized with one of two ${ }^{32} \mathrm{P}$-labeled allele-specific oligonucleotides ( $\mathrm{G}$ gca ggg ggc ttg ttg gga gta aa, final wash: $6 \times \mathrm{SSPE}, 1 \% \mathrm{SDS}, 2 \times 10 \mathrm{~min}$ at $72.5^{\circ} \mathrm{C}$, or T gca ggg ggc ttt ttg gga gta aa, final wash: $6 \times$ SSPE, $1 \%$ SDS, $2 \times 10$ $\min$ at $\left.70.5^{\circ} \mathrm{C}\right)$.

Statistical analysis. Differences in proportions (using either the Fisher's Exact test $(f)$ or the Chi-square statistic), odds ratios (ORs) and $95 \%$ confidence interval (CI) (using the approximation of Woolf) were calculated using InStat ${ }^{\circledR}$ for Macintosh Version 2.0 (GraphPad Software, San Diego, CA). We have presented each analysis without a correction for multiple statistical significance tests on the premise that candidate genes were chosen because of the established differences between alleles in both in vitro and previous clinical association studies. In this context, we have elected to interpret our findings as follows: a $P$ value (two-tailed) between 0.05 and 0.10 indicates a weak association, which probably does not merit further exploration or confirmation; a $P$ value between 0.01 and 0.05 indicates a strong relationship, which may be worth exploring in subsequent or confirmatory studies; a $P$ value between 0.005 and 0.01 indicates a strong association, which is worthy of confirmation; and a $P$ value below 0.005 , which indicates a very strong association between genotype and outcome.

\section{Results}

Study population. The frequency of major infectious and inflammatory complications was retrospectively determined in a cohort of 129 CGD patients. The study population was comprised of 104 patients with XLR CGD (gp91 ${ }^{\text {phox }}$ deficiency) and 25 with AR CGD. The mean length of follow-up was 12.6 $\mathrm{yr}$ (median $9.7 \mathrm{yr}$, range $0.2 \mathrm{yr}-51 \mathrm{yr}$, SD 10.8). In 13 deceased patients, the mean age of death was $11 \mathrm{yr}$ (median $4.5 \mathrm{yr}$, range 2 mo to $35 \mathrm{yr})$.

$56(43.4 \%)$ of the 129 CGD patients developed at least one major complication of either the gastrointestinal or genitourinary (GI/GU) system. These "granulomatous" complications include three major groups: granulomatous ileocolitis $(n=22$, $17.1 \%)$, perirectal abscess or fistula $(n=24,18.6 \%)$, and "obstructive" GI/GU granuloma (combined frequency of major granuloma $n=26,20.2 \%$; including: gastric outlet obstruction $n=20$, esophageal obstruction $n=6$, urinary tract outlet obstruction $n=5$, testicular granuloma $n=2$ ). The frequency of at least one or more chronic GI/GU complications differed between patients with XLR and AR CGD (51/104, 49.0\% vs. 5/25, $20.0 \% ; P=0.009$, OR 3.85, CI 1.35-11.03). In 9 of 129 CGD patients, a rheumatologic or autoimmune process was diagnosed.

The database was analyzed for the frequency and severity of infectious complications of CGD. Documented endpoints were categorized according to the types and location of infection, which included invasive fungal infection (abscess or pneumonia, $n=45,34.9 \%$ ); Gram-negative bacteremia (predominant organism Burkholderia cepacia) or meningitis $(n=$ $19,14.7 \%)$; deep, nonpulmonary bacterial abscess $(n=38$, $29.5 \%)$; and osteomyelitis or septic arthritis $(n=22,17.1 \%)$.

Allelic frequencies of the previously published polymorphic sites in the seven candidate genes chosen for study, MPO (38), MBL (29), Fc $\gamma$ RIIa (55), Fc $\gamma$ RIIIa (34, 35), Fc $\gamma$ RIIIb (36), IL-1RN $(56,57)$, and TNF- $\alpha$ (27), were determined for the entire population of CGD patients and, with two exceptions (IL1RN and FcyRIIIa), reflected the frequencies observed in published control populations.

Granulomatous complications. The strongest association between phenotype and genotype was identified in patients 
with chronic GI or GU complications of CGD. These endpoints are characterized by an abnormal granulomatous or inflammatory process of the GI or GU mucosal surface, resulting in a chronic, debilitating condition (6-11). Variant alleles of MPO, FcyRIIa, and FcyRIIIb each are associated with one or more of these outcomes (Table I) and in combination may contribute additively to susceptibility to one or more of these endpoints (Table II). These results suggest that secondary genetic factors may influence susceptibility to immunologically mediated complications. Overall, the analysis of GI/GU complications indicates the importance of secondary pathways that may be affected in individuals lacking effective NADPH oxidase activity.

In patients homozygous for the MPO G allele at bp -463, a polymorphism in the promoter, which increases transcriptional activity (37), the observed frequency of one or more major GI/ GU complications was $54.1 \%$, which differed from the observed frequency of $27.5 \%$ in patients who were heterozygous or homozygous for the A allele $(P=0.003)$. Examined separately, a positive association was observed between GG homozygotes and perirectal abscess $(25.7 \%$ vs. $7.8 \%$ for heterozygotes and A homozygotes; $P=0.02(f))$ as well as with a major GU or obstructive GI granulomatous complication $(25.7 \%$ vs. $9.8 \% ; P=0.03)$. In an analysis of the MPO polymorphism restricted to the 100 XLR CGD patients, a strong positive association was maintained between the GG genotype and the presence of at least one major GI/GU complication $(59.0 \%$ vs. $33.3 \% ; P=0.01$ ) (Table III). Perirectal abscess occurred in $26.2 \%$ of XLR CGD patients with two G alleles and in $7.7 \%$ of the remaining patients with either AA or AG genotypes $(P=$ $0.03(f))$.

Polymorphisms within two members of the Fc- $\gamma$ receptor gene family, FcyRIIa and Fc $\gamma$ RIIIb, each appear to be associated with the development of GI or urinary tract complications (Table I). The frequency of major GI/GU complications was more common among homozygotes for the $\mathrm{H}$ allele of Fc $\gamma$ RIIa compared with HR heterozygotes or RR homozygotes $(58.1 \%$ vs. $37.9 \% ; P=0.05)$. A very strong positive association between the $\mathrm{HH}$ genotype and major GU or obstructive GI granulomatous complications was observed $(38.7 \%$ vs. $12.6 \%$; $P=0.001$ ), but neither colitis nor perirectal abscess was independently associated with the HH genotype. In an analysis restricted to the XLR CGD patients, the association between the HH genotype of FcyRIIa and granulomas or outlet obstruction was preserved $(39.3 \%$ vs. $13.7 \% ; P=0.005)$ but the marginal overall association with any GI/GU complication loses significance (Table III).

The risk of developing a major GI or GU complication was lower for CGD patients homozygous for the NA1 allele of FcyRIIIb when compared with the risk in patients with the other genotypes, NA1/NA2 or NA2/NA2 (7.7\% vs. $47.4 \%$; $P=0.007(f))$ (Table I). Neither colitis nor GI/GU granulomas complicated the clinical course of the 13 patients homozygous for NA1 ( $0 \%$ vs. $42 / 116,36.2 \% ; P=0.009(f)$, OR 15.40 , CI $0.89-265.86)$. In patients with at least one NA2 allele, colitis developed in $19 \%(P=0.12(f))$ and obstructive granulomas developed in $22.4 \%(P=0.07(f))$. In the XLR CGD cohort (Table III), the frequency of major GI/GU complications was $10.0 \%$ for NA1 homozygotes compared with $53.2 \%$ in the remaining XLR patients $(P=0.02(f))$, again suggesting that the NA2 allele may be a risk factor for immunologically mediated GI/GU complications of CGD.
For a third closely linked $\mathrm{Fc}-\gamma$ receptor, Fc- $\gamma$ RIIIa, there was no overall association with GI/GU complications, but for the subgroup of patients with granulomas and outlet obstruction, a weak association $(P=0.05(f))$ was observed (Table I).

As a result of our analysis, which identified individual associations of each of three different variant genes with granulomatous complications, we undertook an exploratory analysis of combinations of variant alleles in relation to this outcome. In some cases, we observed a potentially greater risk for granulomatous complications in patients who coinherited combinations of variant alleles in comparison with individual associations of this outcome (Table II). For example, the frequency of major GI or GU complications among patients homozygous for allele $\mathrm{H}$ of FcyRIIa but without the protective FcyRIIIb NA1/NA1 genotype was $66.7 \%$ versus $36.4 \%$ for all other combinations of the two genotypes $(P=0.005)$. While 15 $(83.3 \%)$ of the 18 patients with both the HH FoyRIIa genotype and the GG MPO genotype had a history of GI or GU complications, these complications were observed in only 38 $(35.8 \%)$ of the 106 remaining CGD patients $(P=0.0002(f))$. Notably, 17 (94\%) of 18 patients with a GG, HH genotype lacked an NA1 allele. Among these 17 patients, in $88.2 \%$ there was a history of a chronic GI or obstructive complication, yet similar complications were observed in only $36.4 \%$ of the remaining patients $(P<0.0001(f))$. It is also notable that our preliminary analysis of combinations of variant alleles demonstrated less risk associated with a combination of variant alleles compared with either individually. Table II shows that the combination of MPO and FcyRIIIb appears to confer less risk than FcyRIIIb alone.

Rheumatologic and autoimmune disorders. Rheumatologic and AIDs have been reported in both XLR and AR CGD (12-17). In 7 (5.4\%) of 129 patients, an AID was diagnosed, with the distribution of conditions as follows: discoid lupus erythematosus (DLE) in 3, and 1 each of DLE plus Raynaud's, nodular vasculitis, systemic lupus erythematosus with juvenile rheumatoid arthritis, and immune-mediated thrombocytopenia. In two additional patients, there was a strong history of photosensitive rash resembling DLE, but neither was confirmed by skin biopsy. A strong association was observed between the structural variant alleles of MBL and AID (Table IV). All seven patients with confirmed AID were heterozygous for variant MBL alleles $(12.5 \%$ vs. $0 \% ; P=0.003(f))$. When the two patients with a history of photosensitivity were added to the seven documented cases of AID, the strength of the association between structural variant alleles of MBL and AID was maintained $(14.3 \%$ vs. $1.5 \% ; P=0.01(f))$. A weaker association was observed between the variant allele of FcyRIIa and AID, $12.9 \%$ of RR homozygotes versus $3.2 \%$ of HR or HH genotypes $(P=0.06(f))$. Including the two patients with a history of photosensitivity, the observed frequencies for RR versus HR or RR were $16.1 \%$ and $4.2 \%$, respectively ( $P=$ $0.04(f))$.

Five of the nine CGD patients with either AID or photosensitivity had both a variant MBL allele and the homozygous R genotype (27.8\% vs. $3.8 \% ; P=0.003(f))$ (Table IV). Similarly, for the seven patients with a documented AID, the RR genotype was overrepresented ( $22.2 \%$ vs. $2.9 \% ; P=0.009(f)$ ). Among XLR patients with the combined genotypes, the frequency of AID or photosensitivity was $21.4 \%$ (3 of 14 ), compared with $3.5 \%$ ( 3 of 84$)$ in the remaining patients $(P=0.04$ $(f)$, OR 7.36, CI 1.32-41.13). 


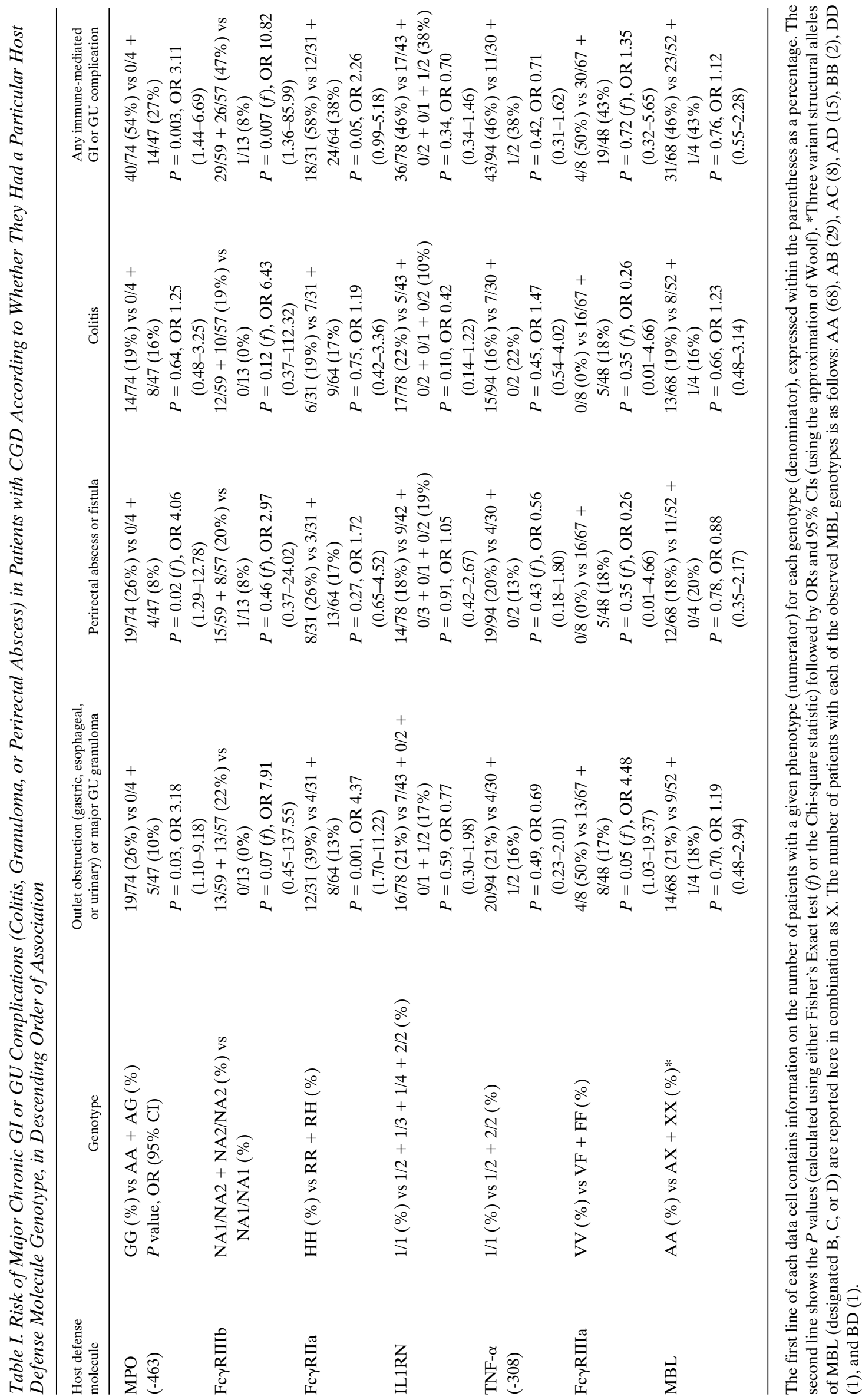




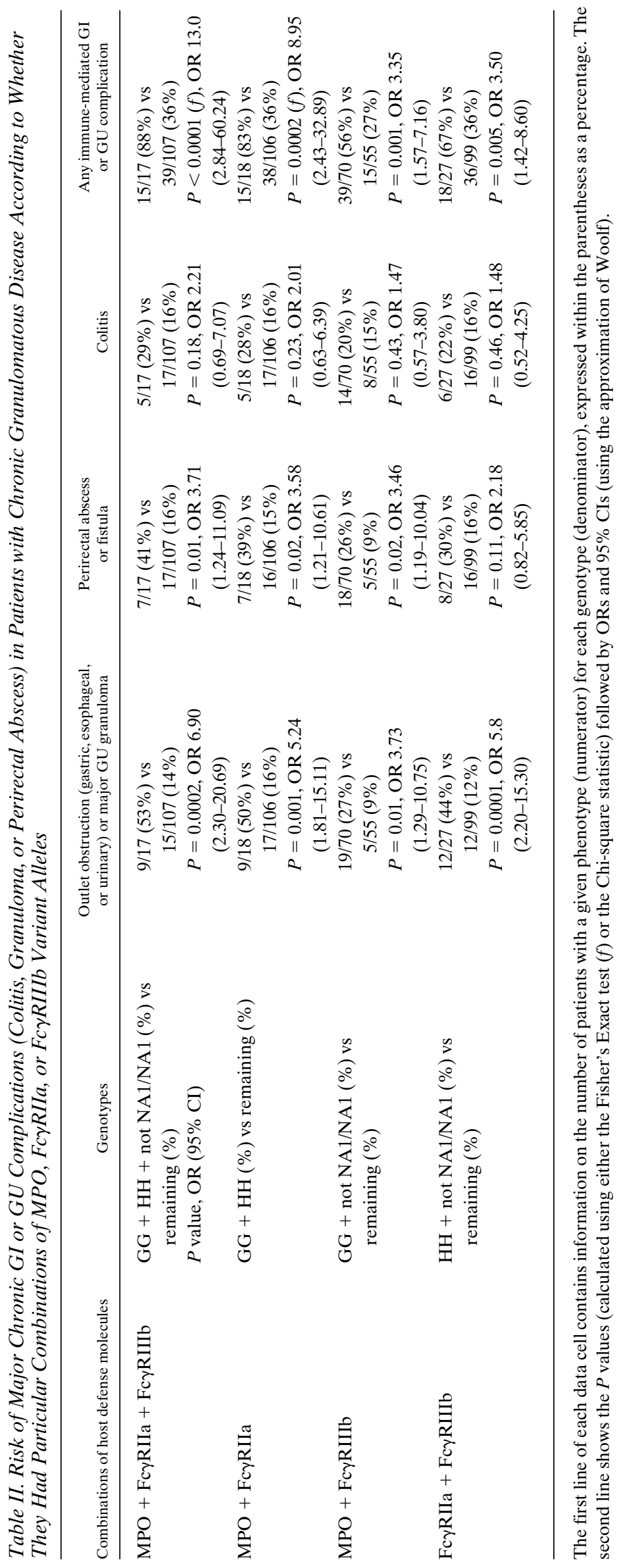




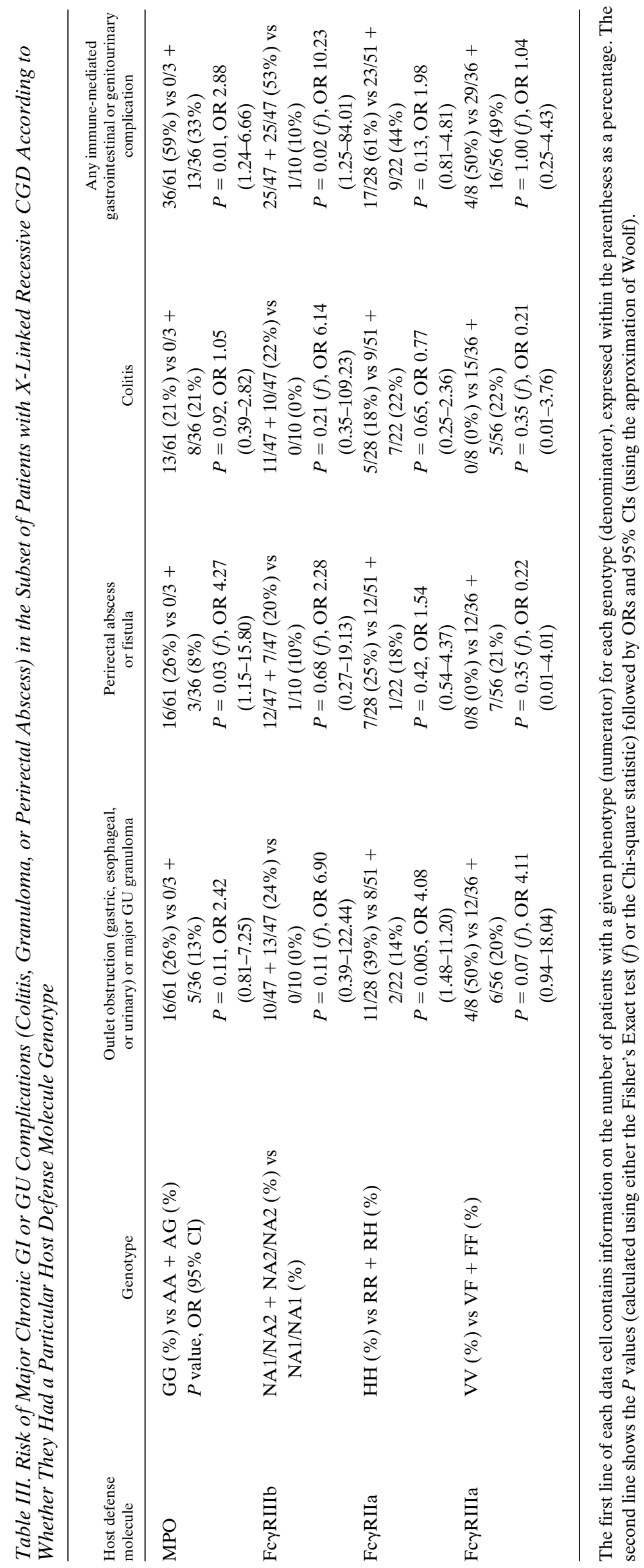


Table IV. Risk of Rheumatologic or Autoimmune Disorders in Patients with CGD According to the Presence of Variant Alleles of the Mannose-Binding Lectin and FcrRIIa, Individually and in Combination

\begin{tabular}{|c|c|c|c|}
\hline Host defense molecule(s) & Genotype & Rheumatologic disorders & Rheumatologic disorders or photosensitivity \\
\hline \multirow[t]{2}{*}{ MBL } & $\mathrm{AX}+\mathrm{XX}(\%)$ vs AA (\%) & $7 / 52+0 / 4(13 \%)$ vs $0 / 68(0 \%)$ & $8 / 52+0 / 4(14 \%) *$ vs $1 / 68(1 \%)$ \\
\hline & $P$ value, OR $(95 \% \mathrm{CI})$ & $P=0.003(f)$, OR $20.76(1.16-372.26)$ & $P=0.01(f)$, OR $11.17(1.35-92.30)$ \\
\hline \multirow[t]{2}{*}{ Fc $\gamma$ RIIa } & RR (\%) vs HH + HR (\%) & $4 / 31(13 \%)$ vs $2 / 31+1 / 64(3 \%)$ & $5 / 31(16 \%)$ vs $3 / 31+1 / 64(4 \%)$ \\
\hline & & $P=0.06(f)$, OR $4.54(0.96-21.57)$ & $P=0.04(f)$, OR $4.38(1.09-17.49)$ \\
\hline \multirow[t]{2}{*}{ MBL + Fc $\gamma$ RIIa } & MBL variants + Fc $\gamma$ RIIa RR vs & $4 / 18(22 \%)$ vs $3 / 105(3 \%)$ & $5 / 18(28 \%)$ vs $4 / 105(4 \%)$ \\
\hline & remaining & $P=0.009(f)$, OR $9.71(1.96-48.03)$ & $P=0.003(f)$, OR $9.71(2.31-40.84)$ \\
\hline
\end{tabular}

Seven patients had well documented autoimmune or rheumatologic disorders: DLE in three, and one each of DLE plus Raynaud's, nodular vasculitis, SLE with juvenile rheumatoid arthritis, and immune-mediated thrombocytopenia. In two additional patients there was a strong history of photosensitive rash resembling DLE, but neither diagnosis was confirmed by skin biopsy. The first line of each data cell contains information on the number of patients with a given phenotype (numerator) for each genotype (denominator), expressed within the parentheses as a percentage. The second line shows the $P$ values (calculated using either the Fisher's Exact test $(f)$ or the Chi-square statistic) followed by odds ratios and $95 \%$ confidence intervals (using the approximation of Woolf). *Eight of these patients were heterozygous for one of the three variant structural alleles of MBL (designated together as X), five heterozygous for allele B, and three heterozygous for allele D.

Infectious complications. Specific infectious complications, including fungal abscess/pneumonia, deep bacterial abscess, osteomyelitis/septic arthritis, and Gram-negative bacteremia/ meningitis were not strongly associated with variant alleles of the seven candidate genes studied. However, two separate genotypes may be of interest for future studies, but in our study did not attain an adequate level of significance: among heterozygotes and homozygotes for the TNF- $\alpha-308$ allele 2, fungal pneumonia/abscesses was observed in 38\% (36/94) of patients compared with $19 \%$ (6 of 32) in homozygotes for wild-type, TNF- $\alpha-308$ allele $1(P=0.04$, OR 2.69 , CI $1.01-$ 7.17). Neither of the two patients homozygous for allele $2 \mathrm{had}$ a history of fungal infection. Nonpulmonary, bacterial abscesses may have an association with patients homozygous for allele $\mathrm{V}$ of the FcyRIIIa (5 of 8, 62.5\%) compared with 32 $(27.8 \%)$ of 115 with one or both F alleles $(P=0.05(f)$, OR 4.32, CI 0.98-19.16).

\section{Discussion}

In search of host genetic factors that modify the clinical phenotype of a primary immunodeficiency, CGD, we analyzed the frequency of variant alleles of seven candidate host defense genes in a cohort of 129 patients. For each candidate gene, previous data suggested that the variant allele(s) biologically altered either the function of the gene product or expression of the gene (38-51). Our findings provide clinical evidence that subtle genetic differences in molecules of innate immunity contribute to interindividual differences in host inflammatory responses in the context of disruption of a primary immunological pathway, the NADPH oxidase. In particular, we observed that polymorphisms of the genes for MPO, FcyRIIa, and FcyRIIIb individually and in combination are associated with the development of chronic gastrointestinal inflammation and granuloma formation in patients with CGD, independent of the CGD subtype. In addition, we observed that variant alleles of MBL and, to a lesser extent, FcyRIIa genotypes are associated with rheumatologic disorders.

Polymorphisms, defined as common variations in a genomic sequence, occur frequently throughout the human genome and in some cases are known to alter either the expression or function of a gene product. Most polymorphisms are phenotypically benign in the normal host. However, in the appropriate environmental and genetic context, a polymorphism may influence susceptibility or outcome in a disease, often by acting upon one or more pathways not disrupted by the primary defect. Therefore, for a given population, polymorphisms may act as susceptibility genes and modify the clinical expression of the disease (58). For patients with CGD, the risk of developing granulomatous complications appears to be influenced by genotypes of myeloperoxidase and Fcy receptors, while the risk of developing a rheumatologic disorder is modified by the presence of variant alleles of mannose binding lectin or FcyRIIa. In both situations, individuals who inherited more than one susceptibility gene had the greatest risk for a granulomatous or rheumatologic disorder. Other groups have examined the association between individual variant alleles and outcomes in other immunocompromised hosts, such as those with HIV (59-61). However, by studying combinations of polymorphic genes, it may be possible to gain even greater insight into the complex genetic traits that contribute to interindividual differences in immune response.

The significance of the findings linking selected variant alleles of candidate genes to outcomes in CGD may shed new light on host defense pathways. For example, the association of granulomatous and GI tract complications in CGD patients with a polymorphism in an upstream regulatory region of MPO is intriguing. Previously, London et al. reported that the GG genotype was associated with an increased risk for lung cancer and hypothesized that differential amounts of MPO may influence the metabolism of tobacco smoke (38). Our findings suggest that the MPO polymorphism may be informative in understanding the role of MPO in host defenses. Recently, MPO has been shown to alter the production or effect of nitric-oxide-derived inflammatory oxidants in activated neutrophils (62). In CGD patients, who have defective or absent NADPH oxidase activity, other sources of oxidants (i.e., xanthine oxidase or mitochondrial cytochrome c or even possibly peroxynitrite) are available for regeneration and interaction with MPO (63-65). Since it has been shown in the X-CGD mouse knockout model that lung vascular injury did not require oxidants generated by the NADPH oxidase, it is not surprising to note the protective effect of L-NMA, a competitive inhibitor of L-arginine, in the X-CGD mouse (66). This last 
point implies that neutrophils may be using an alternative superoxide-generating pathway involving nitric oxide synthesis. Furthermore, it has been suggested that nitrite enhances the antimicrobicidal activity of MPO (67). On the basis of these data, it is possible that the amount of MPO available could affect the regulation of nitric oxide oxidants, resulting in an exuberant response, manifested by ineffective granuloma formation. Several reports have correlated NO with granuloma formation, and in one model significant increases in colonic MPO activity were observed in the chronic phase of granuloma formation (68-70).

In our study, the risk of granuloma formation was influenced by variant alleles of two closely linked genes expressing FcyRIIa and FcyRIIIb (71). The FcyRIIa HH genotype was highly associated with obstructive granuloma formation, whereas individuals homozygous for the NA1 allele of FcyRIIIb had a decreased risk for immunologically mediated granulomatous and GI complications. These data suggest that subtle variations in Fc $\gamma$ receptor function may influence granuloma formation in CGD patients, who are unable to effectively kill invading microorganisms. The role of Fcy receptors in granuloma formation has been demonstrated by the phenotype of the Fc $\gamma R$ chain knockout mouse, which fails to express FcyRI, FcyRIII, and FceRI (72). When infected with Shistosoma mansoni, these mice display enhanced granuloma formation in response to acute infection. In chronically infected mice, extensive tissue fibrosis accompanies an inability to modulate granuloma formation. The augmented granuloma formation appears to be independent of changes in the $\mathrm{T}$ cell proliferative response as well as perturbations in the balance of $\mathrm{TH} 1$ and $\mathrm{TH} 2$ cytokines. Since a nearly identical phenotype is observed in B cell-deficient mice, it has been suggested that antibodies may modulate granulomatous response by triggering the production of antiinflammatory mediators via the Fcy receptors (73).

Rheumatologic disorders have been described in CGD patients and, interestingly, occur in carriers of XLR CGD (12-17, 74). In our study, structural variant alleles of MBL and FcyRIIa were associated with rheumatologic disorders, both individually and in combination. Of note, polymorphisms within each of these genes have been previously reported to be associated with the risk or severity of rheumatologic disorders $(48,75-$ 79). Several lines of evidence support the possibility that one or more variant alleles of MBL and/or FcyRIIa may influence the ability to handle immune complexes or perhaps absorb dying, apoptotic cells. In this context, it is important to note that MBL resembles C1q structurally and functionally; both display a globular head connected to a collagen tail and activate complement. The structural variant forms of MBL (the B, C, and $\mathrm{D}$ alleles) disrupt the triple helix structure of the protein, resulting in markedly decreased levels of circulating MBL and defective activation of complement. It is possible that variant alleles of MBL may be less effective in clearing not only immune complexes but also apoptotic cells. Recently, it has been suggested that the association of $\mathrm{C1q}$ deficiency and lupus disorders may be related to defective clearance of cells undergoing apoptosis (80). A parallel process may explain the overrepresentation of the $\mathrm{R}$ allele of Fc $\gamma$ RIIa in lupus patients with renal disease $(48,78)$. The protein encoded by the variant $\mathrm{R}$ allele has been shown to have low affinity for complexed IgG2 and $\operatorname{IgG3}(46,81)$, which may result in an impaired ability to handle immune complexes and thus contribute to the development of AIDs in CGD patients.
These results suggest that genotype analysis of cohorts with a restriction or ablation of a central component in a host defense pathway makes possible the identification of gene/function relationships in other components that are not easily discernible in individuals with an intact immune system. Furthermore, these observations provide insight into the pathophysiologic mechanisms that underlie the complications that occur as a consequence of a primary disruption of the NADPH oxidase, a critical host defense pathway. A central role for MPO and Fcy receptors in the development of CGD-related granulomas is suggested. In addition, our results support an association between variant alleles of both MBL and FcyRIIa and AIDs. In the future, it may become possible to individualize treatment protocols for CGD patients based on the presence of secondary genetic risk factors. Such an approach might include early intervention strategies designed for patients at high risk for developing obstructive granulomas or AIDs. Clinical association studies, using polymorphisms within host defense genes, are powerful tools for investigating the complex web of host defenses that comprise the innate immune system. In this regard, one may view this approach as a window to observe immunology in vivo.

\section{Acknowledgments}

John O'Mara and Elizabeth Hart helped establish genotype assays. We thank K.K. Marino, the staff of the Immune Deficiency Foundation, and Lisa Vischer, R.N. for help with the collection of clinical information.

T.L. was supported by a Dr. Mildred Scheel Stipendium, Deutsche Krebshilfe e.V. F.M. was supported by the International Medical Student Exchange Program, Amsterdam, The Netherlands.

\section{References}

1. Curnutte, J.T. 1993. Chronic granulomatous disease: the solving of a clinical riddle at the molecular level. Clin. Immunol. Immunopathol. 67:S2-S15.

2. Babior, B.M., J. el Benna, S.J. Chanock, and R.M. Smith. 1997. The NADPH oxidase of leukocytes: the respiratory burst oxidase. In Oxidative Stress and the Molecular Biology of Antioxidant Defenses. J.G. Scandalios, editor. Cold Spring Harbor Laboratory Press, Plainview, NY. 737-783.

3. Segal, A.W. 1996. The NADPH oxidase and chronic granulomatous disease. Mol. Med. Today. 2:129-135.

4. Thrasher, A.J., N.H. Keep, F. Wientjes, and A.W. Segal. 1994. Chronic granulomatous disease. Biochim. Biophys. Acta. 1227:1-24.

5. Gallin, J.I., E.S. Buescher, B.E. Seligmann, J. Nath, T. Gaither, and P. Katz. 1983. NIH conference. Recent advances in chronic granulomatous disease. Ann. Intern. Med. 99:657-674.

6. Rosh, J.R., H.B. Tang, L. Mayer, G. Groisman, S.K. Abraham, and A. Prince. 1995. Treatment of intractable gastrointestinal manifestations of chronic granulomatous disease with cyclosporine. J. Pediatr. 126:143-145.

7. Danziger, R.N., A.T. Goren, J. Becker, J.M. Greene, and S.D. Douglas. 1993. Outpatient management with oral corticosteroid therapy for obstructive conditions in chronic granulomatous disease. J. Pediatr. 122:303-305.

8. Aliabadi, H., R. Gonzalez, and P.G. Quie. 1989. Urinary tract disorders in patients with chronic granulomatous disease. N. Engl. J. Med. 321:706-708.

9. Chin, T.W., E.R. Stiehm, J. Falloon, and J.I. Gallin. 1987. Corticosteroids in treatment of obstructive lesions of chronic granulomatous disease. J. Pediatr. 111:349-352.

10. Werlin, S.L., M.J. Chusid, J. Caya, and H.W. Oechler. 1982. Colitis in chronic granulomatous disease. Gastroenterology. 82:328-331.

11. Varma, V.A., J.T. Sessions, L.B. Kahn, and S. Lipper. 1982. Chronic granulomatous disease of childhood presenting as gastric outlet obstruction. Am. J. Surg. Pathol. 6:673-676.

12. Schmitt, C.P., K. Scharer, R. Waldherr, R.A. Seger, and K.M. Debatin. 1995. Glomerulonephritis associated with chronic granulomatous disease and systemic lupus erythematosus. Nephrol. Dial. Transplant. 10:891-895.

13. Lee, B.W., and H.K. Yap. 1994. Polyarthritis resembling juvenile rheumatoid arthritis in a girl with chronic granulomatous disease. Arthritis Rheum. 37:773-776.

14. Manzi, S., A.H. Urbach, A.B. McCune, H.A. Altman, S.S. Kaplan, T.A. 
Medsger, Jr., and R. Ramsey-Goldman. 1991. Systemic lupus erythematosus in a boy with chronic granulomatous disease: case report and review of the literature. Arthritis Rheum. 34:101-105.

15. Barton, L.L., and C.R. Johnson. 1986. Discoid lupus erythematosus and X-linked chronic granulomatous disease. Pediatr. Dermatol. 3:376-379.

16. Strate, M., F. Brandrup, and P. Wang. 1986. Discoid lupus erythematosus-like skin lesions in a patient with autosomal recessive chronic granulomatous disease. Clin. Genet. 30:184-190.

17. Stalder, J.F., B. Dreno, B. Bureau, and J. Hakim. 1986. Discoid lupus erythematosus-like lesions in an autosomal form of chronic granulomatous disease. Br. J. Dermatol. 114:251-254.

18. Johnston, R.B., and S.L. Newman. 1977. Chronic granulomatous disease. Pediatr. Clin. North Am. 24:365-376.

19. Schapiro, B.L., P.E. Newburger, M.S. Klempner, and M.C. Dinauer. 1991. Chronic granulomatous disease presenting in a 69-year-old man. N. Engl. J. Med. 325:1786-1790.

20. Roos, D., M. de Boer, F. Kuribayashi, C. Meischl, R.S. Weening, A.W. Segal, A. Ahlin, K. Nemet, J.P. Hossle, E. Bernatowska-Matuszkiewicz, et al. 1996. Mutations in the X-linked and autosomal recessive forms of chronic granulomatous disease. Blood. 87:1663-1681.

21. Rae, J., P.E. Newburger, M.C. Dinauer, D. Noack, P.J. Hopkins, R. Kuruto, and J.T. Curnutte. 1998. X-linked chronic granulomatous disease: Mutations in the CYBB gene encoding the gp91-phox component of the respiratory burst oxidase. Am. J. Hum. Genet. 62:1320-1331.

22. Roos, D. 1996. X-CGDbase: a database of X-CGD-causing mutations. Immunol. Today. 17:517-521.

23. 1993. Correlation between genotype and phenotype in patients with cystic fibrosis. The Cystic Fibrosis Genotype-Phenotype Consortium [see comments]. N. Engl. J. Med. 329:1308-1313.

24. Weinmann, A.F., J.M. Schoof, and A.R. Thompson. 1996. Clinical correlates among 49 families with hemophilia A and factor VIII gene inversions. Am. J. Hematol. 51:192-199.

25. Summers, K.M. 1996. Relationship between genotype and phenotype in monogenic diseases: relevance to polygenic diseases. Hum. Mutat. 7:283-293.

26. Weening, R.S., L.H. Adriaansz, C.M. Weemaes, R. Lutter, and D. Roos. 1985. Clinical differences in chronic granulomatous disease in patients with cytochrome b-negative or cytochrome b-positive neutrophils. J. Pediatr. 107:102104.

27. Wilson, A.G., F.S. di Giovine, A.I. Blakemore, and G.W. Duff. 1992. Single base polymorphism in the human tumour necrosis factor alpha (TNF alpha) gene detectable by NcoI restriction of PCR product. Hum. Mol. Genet. 1: 353 .

28. Tarlow, J.K., A.I. Blakemore, A. Lennard, R. Solari, H.N. Hughes, A. Steinkasserer, and G.W. Duff. 1993. Polymorphism in human IL-1 receptor antagonist gene intron 2 is caused by variable numbers of an 86 -bp tandem repeat. Hum. Genet. 91:403-404.

29. Madsen, H.O., P. Garred, J.A. Kurtzhals, L.U. Lamm, L.P. Ryder, S. Thiel, and A. Svejgaard. 1994. A new frequent allele is the missing link in the structural polymorphism of the human mannan-binding protein. Immunogenetics. 40:37-44.

30. Sumiya, M., M. Super, P. Tabona, R.J. Levinsky, T. Arai, M.W. Turner, and J.A. Summerfield. 1991. Molecular basis of opsonic defect in immunodeficient children. Lancet. 337:1569-1570.

31. Turner, M.W., M. Super, S. Singh, and R.J. Levinsky. 1991. Molecular basis of a common opsonic defect. Clin. Exp. Allergy. 21:182-188(Suppl 1).

32. Warmerdam, P.A., J.G. van de Winkel, E.J. Gosselin, and P.J. Capel. 1990. Molecular basis for a polymorphism of human Fc gamma receptor II (CD32). J. Exp. Med. 172:19-25.

33. Jiang, X.M., G. Arepally, M. Poncz, and S.E. McKenzie. 1996. Rapid detection of the Fc gamma RIIA-H/R 131 ligand-binding polymorphism using an allele-specific restriction enzyme digestion (ASRED). J. Immunol. Methods. 199:55-59.

34. Wu, J., J.C. Edberg, P.B. Redecha, V. Bansal, P.M. Guyre, K. Coleman, J.E. Salmon, and R.P. Kimberly. 1997. A novel polymorphism of Fcgamma RIIIa (CD16) alters receptor function and predisposes to autoimmune disease. J. Clin. Invest. 100:1059-1070.

35. Koene, H.R., M. Kleijer, J. Algra, D. Roos, A.E. von dem Borne, and M. de Haas. 1997. Fc gammaRIIIa-158V/F polymorphism influences the binding of IgG by natural killer cell Fc gammaRIIIa, independently of the Fc gammaRIIIa-48L/R/H phenotype. Blood. 90:1109-1114.

36. Hessner, M.J., B.R. Curtis, D.J. Endean, and R.H. Aster. 1996. Determination of neutrophil antigen gene frequencies in five ethnic groups by polymerase chain reaction with sequence-specific primers. Transfusion. 36:895-899.

37. Piedrafita, F.J., R.B. Molander, G. Vansant, E.A. Orlova, M. Pfahl, and W.F. Reynolds. 1996. An Alu element in the myeloperoxidase promoter contains a composite SP1-thyroid hormone-retinoic acid response element. J. Biol. Chem. 271:14412-14420.

38. London, S.J., T.A. Lehman, and J.A. Taylor. 1997. Myeloperoxidase genetic polymorphism and lung cancer risk. Cancer Res. 57:5001-5003

39. Kroeger, K.M., K.S. Carville, and L.J. Abraham. 1997. The -308 tumor necrosis factor-alpha promoter polymorphism effects transcription. Mol. Immunol. 34:391-399.
40. Wilson, A.G., J.A. Symons, T.L. McDowell, H.O. McDevitt, and G.W. Duff. 1997. Effects of a polymorphism in the human tumor necrosis factor alpha promoter on transcriptional activation. Proc. Natl. Acad. Sci. USA. 94:31953199 .

41. McGuire, W., A.V. Hill, C.E. Allsopp, B.M. Greenwood, and D. Kwiatkowski. 1994. Variation in the TNF-alpha promoter region associated with susceptibility to cerebral malaria. Nature. 371:508-510.

42. Cabrera, M., M.A. Shaw, C. Sharples, H. Williams, M. Castes, J. Convit, and J.M. Blackwell. 1995. Polymorphism in tumor necrosis factor genes associated with mucocutaneous leishmaniasis. J. Exp. Med. 182:1259-1264.

43. Mansfield, J.C., H. Holden, J.K. Tarlow, F.S. Di Giovine, T.L. McDowell, A.G. Wilson, C.D. Holdsworth, and G.W. Duff. 1994. Novel genetic association between ulcerative colitis and the anti-inflammatory cytokine interleukin-1 receptor antagonist. Gastroenterology. 106:637-642.

44. Blakemore, A.I., P.F. Watson, A.P. Weetman, and G.W. Duff. 1995. Association of Graves' disease with an allele of the interleukin-1 receptor antagonist gene. J. Clin. Endocrinol. Metab. 80:111-115.

45. Danis, V.A., M. Millington, V.J. Hyland, and D. Grennan. 1995. Cytokine production by normal human monocytes: inter-subject variation and relationship to an IL-1 receptor antagonist (IL-1Ra) gene polymorphism. Clin. Exp. Immunol. 99:303-310.

46. Warmerdam, P.A., J.G. van de Winkel, A. Vlug, N.A. Westerdaal, and P.J. Capel. 1991. A single amino acid in the second Ig-like domain of the human Fc gamma receptor II is critical for human IgG2 binding. J. Immunol. 147:13381343.

47. Bredius, R.G., B.H. Derkx, C.A. Fijen, T.P. de Wit, M. de Haas, R.S. Weening, J.G. van de Winkel, and T.A. Out. 1994. Fc gamma receptor IIa (CD32) polymorphism in fulminant meningococcal septic shock in children. $J$. Infect. Dis. 170:848-853.

48. Duits, A.J., H. Bootsma, R.H. Derksen, P.E. Spronk, L. Kater, C.G. Kallenberg, P.J. Capel, N.A. Westerdaal, G.T. Spierenburg, F.H. Gmelig-Meyling, et al. 1995. Skewed distribution of IgG Fc receptor IIa (CD32) polymorphism is associated with renal disease in systemic lupus erythematosus patients. Arthritis Rheum. 38:1832-1836.

49. Norris, C.F., S. Surrey, G.R. Bunin, E. Schwartz, G.R. Buchanan, and S.E. McKenzie. 1996. Relationship between Fc receptor IIA polymorphism and infection in children with sickle cell disease. J. Pediatr. 128:813-819.

50. Salmon, J.E., S.S. Millard, N.L. Brogle, and R.P. Kimberly. 1995. Fc gamma receptor IIIb enhances $\mathrm{Fc}$ gamma receptor IIa function in an oxidantdependent and allele-sensitive manner. J. Clin. Invest. 95:2877-2885.

51. Salmon, J.E., J.C. Edberg, N.L. Brogle, and R.P. Kimberly. 1992. Allelic polymorphisms of human $\mathrm{Fc}$ gamma receptor IIA and $\mathrm{Fc}$ gamma receptor IIIB Independent mechanisms for differences in human phagocyte function. J. Clin. Invest. 89:1274-1281.

52. Dinauer, M.C., E.A. Pierce, G.A. Bruns, J.T. Curnutte, and S.H. Orkin. 1990. Human neutrophil cytochrome b light chain (p22-phox): gene structure, chromosomal location, and mutations in cytochrome-negative autosomal recessive chronic granulomatous disease. J. Clin. Invest. 86:1729-1737.

53. Patino, P.J., J. Rae, R. Erickson, J. Ding, D. Garcia de Olarte, and J.T. Curnutte. 1996. Molecular characterization of autosomal recessive chronic granulomatous disease caused by a deficiency of the NADPH oxidase component p67-phox. Blood. 88:622a.

54. Roesler, J., A. Gorlach, J. Rae, P.J. Hopkins, P. Patino, P. Lee, J.T. Curnutte, and S.J. Chanock. 1995. Recombination events between the normal P47phox gene and a highly homologous pseudogene are the main cause of autosomal recessive chronic granulomatous disease (CGD). Blood. 86:260a.

55. Sanders, L.A., J.G. van de Winkel, G.T. Rijkers, M.M. VoorhorstOgink, M. de Haas, P.J. Capel, and B.J. Zegers. 1994. Fc gamma receptor IIa (CD32) heterogeneity in patients with recurrent bacterial respiratory tract infections. J. Infect. Dis. 170:854-861.

56. Danis, V.A., M. Millington, Q. Huang, V. Hyland, and D. Grennan. 1995. Lack of association between an interleukin-1 receptor antagonist gene polymorphism and systemic lupus erythematosus. Dis. Markers. 12:135-139.

57. Hacker, U.T., M. Gomolka, E. Keller, A. Eigler, C. Folwaczny, H. Fricke, E. Albert, K. Loeschke, and S. Endres. 1997. Lack of association between an interleukin-1 receptor antagonist gene polymorphism and ulcerative colitis. Gut. 40:623-627.

58. Childs, B., R.E. Moxon, and J.A. Winkelstein. 1992. Genetics and Infectious Diseases. In The Genetic Basis of Common Diseases. R.A. King, J.I. Rotter, and A.G. Motulsky, editors. Oxford University Press, New York. 71-91.

59. Winkler, C., W. Modi, M.W. Smith, G.W. Nelson, X. Wu, M. Carrington, M. Dean, T. Honjo, K. Tashiro, D. Yabe, et al. 1998. Genetic restriction of AIDS pathogenesis by an SDF-1 chemokine gene variant. ALIVE Study, Hemophilia Growth and Development Study (HGDS), Multicenter AIDS Cohort Study (MACS), Multicenter Hemophilia Cohort Study (MHCS), San Francisco City Cohort (SFCC) [see comments]. Science. 279:389-393.

60. Dean, M., M. Carrington, C. Winkler, G.A. Huttley, M.W. Smith, R. Allikmets, J.J. Goedert, S.P. Buchbinder, E. Vittinghoff, E. Gomperts, et al. 1996. Genetic restriction of HIV-1 infection and progression to AIDS by a deletion allele of the CKR5 structural gene. Hemophilia Growth and Development Study, Multicenter AIDS Cohort Study, Multicenter Hemophilia Cohort Study, San Francisco City Cohort, ALIVE Study [see comments] [published erratum 
appears in Science. 1996. 274(5290):1069]. Science. 273:1856-1862.

61. Zimmerman, P.A., A. Buckler-White, G. Alkhatib, T. Spalding, J. Kubofcik, C. Combadiere, D. Weissman, O. Cohen, A. Rubbert, G. Lam, et al. 1997. Inherited resistance to HIV-1 conferred by an inactivating mutation in $\mathrm{CC}$ chemokine receptor 5: studies in populations with contrasting clinical phenotypes, defined racial background, and quantified risk. Mol. Med. 3:23-36.

62. Eiserich, J.P., M. Hristova, C.E. Cross, A.D. Jones, B.A. Freeman, B. Halliwell, and A. van der Vliet. 1998. Formation of nitric oxide-derived inflammatory oxidants by myeloperoxidase in neutrophils. Nature. 391:393-397.

63. Sharpe, M.A., and C.E. Cooper. 1998. Reactions of nitric oxide with mitochondrial cytochrome c: a novel mechanism for the formation of nitroxyl anion and peroxynitrite. Biochem. J. 332:9-19.

64. Kukreja, R.C., and M.L. Hess. 1992. The oxygen free radical system: from equations through membrane-protein interactions to cardiovascular injury and protection. Cardiovasc. Res. 26:641-655.

65. Pryor, W.A., and G.L. Squadrito. 1995. The chemistry of peroxynitrite: a product from the reaction of nitric oxide with superoxide [see comments]. Am J. Physiol. 268:L699-L722.

66. Kubo, H., D. Morgenstern, W.M. Quinian, P.A. Ward, M.C. Dinauer, and C.M. Doerschuk. 1996. Preservation of complement-induced lung injury in mice with deficiency of NADPH oxidase. J. Clin. Invest. 97:2680-2684.

67. Klebanoff, S.J. 1993. Reactive nitrogen intermediates and antimicrobial activity: role of nitrite. Free Radic. Biol. Med. 14:351-360.

68. Setoguchi, K., M. Takeya, T. Akaike, M. Suga, R. Hattori, H. Maeda, M. Ando, and K. Takahashi. 1996. Expression of inducible nitric oxide synthase and its involvement in pulmonary granulomatous inflammation in rats. $A m$. J. Pathol. 149:2005-2022.

69. Iuvone, T., R. Carnuccio, and M. Di Rosa. 1994. Modulation of granuloma formation by endogenous nitric oxide. Eur. J. Pharmacol. 265:89-92.

70. Yamada, T., R.B. Sartor, S. Marshall, R.D. Specian, and M.B. Grisham. 1993. Mucosal injury and inflammation in a model of chronic granulomatous colitis in rats. Gastroenterology. 104:759-771.

71. van de Winkel, J.G., and P.J. Capel. 1993. Human IgG Fc receptor heterogeneity: molecular aspects and clinical implications. Immunol. Today. 14: 215-221.

72. Takai, T., M. Li, D. Sylvestre, R. Clynes, and J.V. Ravetch. 1994. FcR gamma chain deletion results in pleiotrophic effector cell defects. Cell. 76:519529.

73. Jankovic, D., A.W. Cheever, M.C. Kullberg, T.A. Wynn, G. Yap, P. Caspar, F.A. Lewis, R. Clynes, J.V. Ravetch, and A. Sher. 1998. CD4+ T cellmediated granulomatous pathology in schistosomiasis is downregulated by a B cell-dependent mechanism requiring Fc receptor signaling. J. Exp. Med. 187: 619-629.

74. Brandrup, F., C. Koch, M. Petri, M. Schiodt, and K.S. Johansen. 1981 Discoid lupus erythematosus-like lesions and stomatitis in female carriers of X-linked chronic granulomatous disease. Br. J. Dermatol. 104:495-505.

75. Davies, E.J., L.S. Teh, J. Ordi-Ros, N. Snowden, M.C. Hillarby, A. Hajeer, R. Donn, P. Perez-Pemen, M. Vilardell-Tarres, and W.E. Ollier. 1997. A dysfunctional allele of the mannose binding protein gene associates with systemic lupus erythematosus in a Spanish population. J. Rheumatol. 24:485-488.

76. Sullivan, K.E., C. Wooten, D. Goldman, and M. Petri. 1996. Mannosebinding protein genetic polymorphisms in black patients with systemic lupus erythematosus. Arthritis Rheum. 39:2046-2051.

77. Davies, E.J., N. Snowden, M.C. Hillarby, D. Carthy, D.M. Grennan, W. Thomson, and W.E. Ollier. 1995. Mannose-binding protein gene polymorphism in systemic lupus erythematosus [see comments]. Arthritis Rheum. 38:110-114.

78. Haseley, L.A., J.J. Wisnieski, M.R. Denburg, A.R. Michael-Grossman, E.M. Ginzler, M.F. Gourley, J.H. Hoffman, R.P. Kimberly, and J.E. Salmon. 1997. Antibodies to C1q in systemic lupus erythematosus: characteristics and relation to Fc gamma RIIA alleles. Kidney Int. 52:1375-1380.

79. Rascu, A., R. Repp, N.A. Westerdaal, J.R. Kalden, and J.G. van de Winkel. 1997. Clinical relevance of Fc gamma receptor polymorphisms. Ann. NY. Acad. Sci. 815:282-295.

80. Botto, M., C. Dell'Agnola, A.E. Bygrave, E.M. Thompson, H.T. Cook, F. Petry, M. Loos, P.P. Pandolfi, and M.J. Walport. 1998. Homozygous C1q deficiency causes glomerulonephritis associated with multiple apoptotic bodies [see comments]. Nat. Genet. 19:56-59.

81. Clark, M.R., S.G. Stuart, R.P. Kimberly, P.A. Ory, and I.M. Goldstein. 1991. A single amino acid distinguishes the high-responder from the lowresponder form of Fc receptor II on human monocytes. Eur. J. Immunol. 21: 1911-1916. 